\title{
Experiments to Separate the Effect of Texture on Anisotropy of Pipeline Steel
}

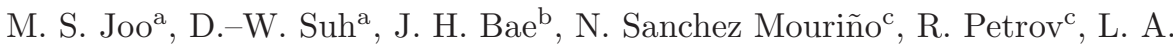 \\ I. Kestens ${ }^{\mathrm{c}}$, H. K. D. H. Bhadeshia ${ }^{\mathrm{a}, \mathrm{d}}$ \\ ${ }^{a}$ Graduate Institute of Ferrous Technology, Pohang University of Science and Technology, \\ Republic of Korea \\ ${ }^{b}$ Technical Research Laboratories, POSCO, Korea \\ ${ }^{c}$ Ghent University, Materials Science and Engineering, Belgium \\ ${ }^{d}$ Materials Science and Metallurgy, University of Cambridge, U. K.
}

\begin{abstract}
Many linepipe steels exhibit a variation in mechanical properties as a function of the orientation of the test sample relative to the rolling and transverse directions of the steel plate. Such anisotropy limits the optimum design and exploitation of the steel, and its occurrence has been attributed to effects such as microstructural banding and the associated delamination during fracture, and unfavourably oriented ferrite cleavage-planes. It is often difficult to separate the factors, but an experiment has been designed and implemented to study the role of crystallographic texture in isolation. It is demonstrated that the texture plays a major role in influencing the anisotropy of Charpy test energy.

Keywords: pipeline steel, anisotropy, crystallographic texture, memory effect

\section{Introduction}

The anisotropy in the mechanical properties of hot-rolled steel which is subsequently made into pipes compromises the optimum design of pipes $[1,2]$. In the case of spiral-welded pipes, the circumferential direction lies at $45^{\circ}$ to that in which the steel is rolled, an orientation which has the lowest toughness and yet is exposed to the highest loading from hoop stress [2-5].

Factors such as aligned inclusions, elongated grains and crystallographic texture all influence the orientation dependence of mechanical properties; there is an extensive literature on the subject, for example, [6-23]. Crystallographic
\end{abstract}

Email address: dongwoo1@postech.ac.kr (D.-W. Suh) 
texture can influence anisotropy by increasing the probability of cleavage planes being parallel to the fracture plane of Charpy specimens [12, 19, 24], or by biasing the slip systems available for ductile fracture [19]. However, the role of crystallography is not well-established. Some studies indicate a lack of correlation between the texture and the orientation dependence of Charpy properties $[11,13,25,26]$.

It is in practice difficult to separate the roles of the individual causes of anisotropy, partly because most studies of linepipe steels are conducted on the steel supplied in its final state, with a determined microscopic and crystallographic structure. In a recent study on a specific X80 steel where inclusion alignment is absent $[27,28]$, it was established that the anisotropy of Charpy properties can be attributed to a combination of delamination (caused by microstructural banding and variations in crystallography between adjacent bands) and by crystallographic texture. The latter cause was considered to be secondary in importance, a conclusion reached by testing unconventional notch orientations. However, the purpose here was to obtain further supporting evidence by designing two experiments in which microstructural banding is eliminated but the crystallographic texture retained.

\section{Method}

Many of the experimental details have been published previously [27] and hence only new procedures and repeated information which adds to clarity are presented here. The X80 steel chemical composition and processing parameters are listed in Table 1.

A heat treatment was designed with the purpose of eliminating microstructural banding while preserving the crystallographic texture. Banding arises because of chemical segregation during solidification, particularly of manganese. The concentration variations inherited from solidification then spread out into layers during the deformation used to shape the cast form into steel plates. The transformation of austenite into ferrite then occurs first in the manganesedepleted regions, and as a result carbon is partitioned into the manganese enriched regions, when then transforms in harder products. It is well known that such banding can be avoided by rapid cooling since transformation is suppressed to greater undercooling so that nucleation then occurs in all locations, thus avoiding the segregation of carbon [29]. The heat treatment selected was therefore to quench the samples from the austenitisation temperature. 
The austenitisation treatment clearly must be above the $A e 3$ temperature which was calculated to be $840^{\circ} \mathrm{C}$ using MTDATA [30] and the TCFE4 database (allowing austenite, ferrite, cementite and alloy carbides to exist, and the components $\mathrm{Fe}, \mathrm{C}, \mathrm{Mn}, \mathrm{Si}, \mathrm{P}, \mathrm{S}, \mathrm{Nb}, \mathrm{Ni}, \mathrm{Mo}, \mathrm{Ti}, \mathrm{Al}, \mathrm{N})$. Dilatometric experiments revealed an $A c 3$ temperature of $860^{\circ} \mathrm{C}$ for heating at $5^{\circ} \mathrm{Cs}^{-1}$ [28] so the austenitisation temperature was chosen to be $890^{\circ} \mathrm{C}$ and the austenitisation time, $10 \mathrm{~min}$. The temperature needs to be as low as possible so that significant austenite grain growth is prevented, and hence the original ferrite transformation texture is retained on quenching, through what is known as a texture memory effect $[31,32]$.

Orientation distribution functions (ODFs) were measured using Co- $\mathrm{K}_{\alpha} \mathrm{X}_{-}$ ray diffraction. The samples for this purpose were prepared using $6 \mu \mathrm{m}$ diamond paste for the final polish, and the distributions of the $\{110\},\{200\},\{211\}$ and $\{311\}$ poles were used to generate the ODFs. Samples for electron backscatter diffraction (EBSD) were mechanically polished using colloidal silica in the final stage of preparation.

\section{Results and discussion}

One of the most important anisotropies present in linepipe steels is that of Charpy impact toughness as a function of the orientation of the notch with respect to the plate axes. It has been shown [27] that the sharp minima observed in toughness within the ductile-brittle transition temperature range $(\approx-40$ to $-60^{\circ} \mathrm{C}$ ) as a function of orientation is related to two factors, the lack of delamination during fracture, and a propensity for the cleavage planes in the banded microstructure to align with the macroscopic fracture plane of the Charpy specimen. Supporting information, including microstructure, orientation maps and mechanical properties have already been reported [27]. Fig. 1 summarises the observations and much more detail is available in the original publication [27].

Similar experiments were repeated after reaustenitising and quenching the as-received steel. The resulting microstructure is illustrated in Fig. 2 as a function of orientation relative to the plate axes including the rolling direction. The essential point from the comparison against the banded structure illustrated in Fig. 2a is that the heat treatment has eliminated the microstructural anisotropy in the form of banding. As a consequence, the set of Charpy impact fractographs shown in Fig. 3 shows the absence of delamination or fissuring as it is sometimes called (cf. Fig. 1d). 
In spite of the elimination of banding and delamination, the variation in Charpy toughness in the impact transition region, as a function of sample orientation is still very strong. The raw data are shown in Fig. 4a. The data are also shown in the form of plots where the radial distance from centre corresponds to the energy absorbed, so that energies recorded from an isotropic sample would follow the quadrant of a circle. Figs $4 \mathrm{~b}, \mathrm{c}$ show that the anisotropies of the as-received and heat-treated samples are similar. This is because the crystallographic texture has not changed much as a consequence of the heat-treatment given to the as-received steel, Figs 5,6. The figures are represented using identical colour scales, and while there are differences in the strength of the textures, both the as-received and quenched samples show similar patterns of behaviour in each of the sections of the orientation distribution maps.

This is a remarkable result given that the dramatic nature of the austenitisation and quenching heat treatment, but can be explained on the basis of a well-known memory effect [31, 32]. There are strong orientation relationships generated when austenite transforms into ferrite. This applies also to the formation of austenite during heating from a fully ferritic structure. As a result, the original texture generated in the pipeline steel which arises because of the existence of strong orientation relationships between the nucleating phase (austenite during heating) and the existing ferrite. This relationship persists during both forward and reverse transformation, unless significant austenite grain growth occurs during prolonged heat-treatment or due to austenitisation at a very high temperature. For the present purposes, this observation provides a unique way of proving the large effect of texture in the absence of overlap of information with phenomena such as microstructural anisotropy or banding.

The role of texture is in terms of the alignment of $\{100\}_{\alpha}$ planes in the polycrystalline steel, along specific directions relative to the rolling direction. The propensity of such cleavage-planes along a particular orientation must make for easy fracture. Fig. 7 show that the distributions of these planes relative to the rolling direction are comparable for the as-received and heat-treated steels.

The totality of the results from our previous work [27] and the new experiments have been summarised in Fig. 8 using an index defined as follows:

$$
\text { Anisotropy index }=\left(J_{\text {maximum }}-J_{\text {minimum }}\right) / J_{\text {overall maximum }}
$$

where $J$ represents the energy absorbed during a Charpy test and the subscripts 'maximum' and 'minimum' represent the values of $J$ at a given test temperature. 
Comparison of anisotropy index of as-received steel with the heat treated one without the influence of delamination shows with clarity that crystallographic texture has a profound influence on the Charpy anisotropy in the X80 steel studied here.

The density of high-misorientation grain boundaries $\left(>15^{\circ}\right)$ did not vary significantly with orientation relative to the plate axes; these results are not reported here for brevity but are available in [28].

Finally, it is noted that the general reduction in Charpy toughness in the quenched samples relative to the as-received pipe is because the former is much harder at $296 \pm 6 \mathrm{HV}$ when compared with the thermomechanically processed pipe which has a hardness of $220 \pm 4 \mathrm{HV}$.

\subsection{Isothermal Transformation}

An independent experiment was conducted in which X80 steel similar to that described in Table 1 was austenitised at $900^{\circ} \mathrm{C}$ for $20 \mathrm{~min}$ and then isothermally transformed at $400^{\circ} \mathrm{C}$ for $10 \mathrm{~min}$ followed by air cooling, to generate the bainitic microstructure illustrated in Fig. 9a; microstructural banding is absent. A full texture evaluation was carried out [33] but the $\phi_{2}=45^{\circ}$ sections of the orientation distribution functions, for the samples before and after heat-treatment are also illustrated in Fig. 9b,c. It is evident that the texture is weakened by the heat treatment, more so than in when the steel was transformed into martensite. The Charpy tests (Fig. 10) confirm that toughness-anisotropy in the impact transition regions remains but is reduced, consistent with the change in texture.

\section{Conclusions}

Unique experiments have been designed to retain the crystallographic texture of X80 linepipe steel whilst eliminating microstructural banding and delamination during fracture. As a consequence, it is possible to reach the following conclusions:

(a) There exists a memory effect which reproduces the crystallographic texture of processed X80 steel after austenitisation under conditions which avoid significant austenite grain growth, followed by quenching to room temperature. 
(b) The role of the texture is uniquely established as a major cause of Charpy toughness anisotropy, without clouding the interpretation with the possible influence of delamination or microstructural banding. The anisotropy is particularly pronounced in the temperature range where there is a ductile to brittle transition in the mode of fracture.

Acknowledgments: The authors are grateful for support from the POSCO Steel Innovation Programme, and to the World Class University Programme of the National Research Foundation of Korea, Ministry of Education, Science and Technology, project number R32-2008-000-10147-0. 


\section{References}

[1] E. Torselletti, L. Vitali, R. Bruschi: Design criteria versus line pipe requirements for offshore pipelines: in: Proceedings of Super-High Strength Steels: Associazione Italian di Metallurgica, Rome, Italy, 2005: pp. 1-18.

[2] K. Kim, J.-H. Bae: Metallurgical and process parameters for commercial production of high toughness API-X80 grade hot rolled strips: in: 2008 7th International Pipeline Conference: Vol. 3: ASME, New York, USA, 2008: pp. $167-173$.

[3] D. H. Seo, C. M. Kim, J. Y. Yoo, K. B. Kang: Microstructure and mechanical properties of X80/X100 grade plates and pipes: in: Seventeenth International Offshore and Polar Engineering Conference: The International Society of Offshore and Polar Engineers, California, USA, 2007: pp. 3301-3306.

[4] D. Stalheim, K. Barnes, D. McCutcheon: Alloy designs for high strength oil and gas transmission linepipe steels: in: Microalloyed Steels for the Oil and Gas Industry: TMS, Warrendale, Pennsylvania, USA, 2007: pp. 73-108.

[5] K. B. Kang, H. H. Bae, W. Y. Choo: Effect of thermomechanical processing parameters on mechanical properties and microstructure of API-X80 grade hot rolled strips: in: R. Denys (Ed.), Proceedings of the 4th International Pipeline Technology Conference: Vol. 4: Scientific Surveys Ltd., Ostend, Belgium, 2004: pp. 1689-1699.

[6] C. E. Sims: Trans. Met. Soc. AIME 215 (1959) 367-393.

[7] J. M. Hodge, R. H. Frazier, G. W. Boulger: Trans. Metall. Soc. AIME 215 (1959) 745-753.

[8] T. J. Baker, J. A. Cameron: Journal of the Iron and Steel Institute 210 (1972) 680-690.

[9] P. C. Wilson, Y. V. Murty, T. Z. Kattamis, R. Mehrabian: Metals Technology 2 (1975) 241-244.

[10] Y. I. Matrosov, I. E. Polyakov: Stal 2 (1976) 162-167.

[11] B. Mintz, W. B. Morrison, P. P. Morris, G. J. Davies: The influence of texture on the tensile and impact properties of controlled steels: in: G. J. 
Davies (Ed.), Texture and Properties of Materials: The Metals Society, London, U.K., 1976: pp. 224-234.

[12] H. Inagaki, K. Kurihara, I. Kozasu: Trans. Iron Steel Institute of Japan 17 (1977) $75-81$.

[13] B. Mintz, W. B. Morrison, P. I. Welch, G. J. Davies: The relative contributions of texture and grain shape to the properties of warm-rolled Fe-Mn alloys: in: G. Gottstein, K. Lucke (Eds.), Texture of Materials: Vol. 2: Springer-Verlag, Berlin, Germany, 1978: pp. 465-474.

[14] S. J. Garwood: The effect of temperature, orientation and constraint on the toughness of A 533 B Class I steel: in: Application of Fracture Mechanics to Materials and Structures: Martinus Nijhoff Publishers, Leiden, Holland, 1984: pp. 939-950.

[15] G. S. Kramer, G. M. Wilkowski, W. A. Maxey: Flaw tolerance of spiralwelded line pipe: Tech. Rep. L51514: American Gas Association: Washington, D. C., USA (1987).

[16] V. A. Burnos, T. P. Vaschilo, L. E. Balandina: Industrial Laboratory (USSR) 54 (1988) 548-550.

[17] G. M. Wilkowski, J. Ahmad, F. Brust, N. Ghadiali, P. Krishnaswamy, M. Landow, C. W. Marschall, P. Scott, P. Vieth: Short cracks in piping and piping welds: Tech. Rep. NUREG/CR-4599-Vol.1-No.1; BMI-2173Vol.1-No.1: Nuclear Regulatory Commission: Ohio, USA (1991).

[18] P. Krishnaswamy, P. Scott, R. Mohan, S. Rahman, Y. H. Choi, F. Brust, T. Kilnski, N. Ghadiali, C. Marchall, G. Wilkowski: Fracture behavior of short circumferentially surface-cracked pipe: Tech. Rep. NUREG/CR-6298: Nuclear Regulatory Commission: Ohio, U. S. A. (1995).

[19] G. J. Baczynski, J. J. Jonas, L. E. Collins: Metallurgical \& Materials Transactions A 30 (1999) 3045-3054.

[20] R. Petrov, O. L. Garcia, N. S. Mourino, L. Kestens, J. H. Bae, K. B. Kang: Materials Science Forum 558-559 (2007) 1429-1434.

[21] R. H. Petrov, O. L. Garcia, J. J. L. Mulders, A. C. C. Reis, J. H. Bae, L. A. I. Kestens, Y. Houbaert: Materials Science Forum 550 (2007) 625630 . 
[22] S. M. Far: Advanced Materials Research 287-290 (2011) 2161-2164.

[23] I. Pyshmintsev, A. Gervasyev, R. H. Petrov, V. C. Olalla, L. A. I. Kestens: Materials Science Forum 702-703 (2012) 770-773.

[24] J. B. Ju, J. S. Lee, J. I. Jang: Materials Letters 61 (2007) 5178-5180.

[25] D. M. Fegredo, B. Faucher, M. T. Shehata: Influence of inclusion content, texture and microstructure on the toughness anisotropy of low carbon steels: in: Strength of Metals and Alloys: Vol. 2: Pergamon Press, Oxford, U. K., 1985: pp. 1127-1132.

[26] O. L. Garcia, R. Petrov, J. H. Bae, L. Kestens, K. B. Kang: Advanced Materials Research 15-17 (2007) 840-845.

[27] M. S. Joo, D. W. Suh, J. H. Bae, H. K. D. H. Bhadeshia: Materials Science \& Engineering A 546 (2012) 314-322.

[28] M. S. Joo: Anisotropy of charpy properties in linepipe steels: Ph.D. thesis: Pohang University of Science and Technology: Pohang, Republic of Korea (2012).

[29] H. Tamehiro, T. Takeda, S. Matsuda, K. Yamamoto, N. Okumura: Trans. ISIJ 25 (1985) 982-988.

[30] NPL: MTDATA: Software, National Physical Laboratory, Teddington, U.K. (2006).

[31] S. T. Kimmins, D. J. Gooch: Metal Science 17 (1983) 519-532.

[32] I. Lischewski, D. M. Kirch, A. Ziemons, G. G. (ed. A. D. Rollett): Applications of Texture Analysis: John Wiley and Sons Inc., New Jersey, USA, 2008: Ch. 10: Investigation of the $\alpha-\gamma-\alpha$ phase transformation in steel: high-temperature in situ EBSD measurements: pp. 95-102.

[33] N. S. Mouriño: Crystallographically controlled mechanical anisotropy of pipeline steel: Ph.D. thesis: University of Ghent: Belgium (2011). 
Table 1: Chemical composition (wt\%) and thermomechanical processing conditions. $A r_{3}$ represents the temperature at which austenite begins to decompose during cooling. Please note that the exact chemical composition and processing is proprietary information.

\begin{tabular}{ccccccc}
\hline $\mathrm{C}$ & $\mathrm{Mn}$ & $\mathrm{Si}$ & $\mathrm{P}+\mathrm{S}$ & $\mathrm{Nb}+\mathrm{Ni}+\mathrm{Mo}$ & $\mathrm{Ti}+\mathrm{Al}$ & $\mathrm{N}$ \\
$<0.08$ & $<2.0$ & 0.21 & $<0.013$ & $<0.8$ & 0.03 & $<0.0036$ \\
\hline Reheating temperature & & $1100-1180^{\circ} \mathrm{C}$ & & \\
Cooling start-temperature & Above $A r_{3}$ & & \\
Finish rolling temperature & Above $A r_{3}$ & & \\
Coiling temperature & $>500^{\circ} \mathrm{C}$ & & \\
\hline
\end{tabular}


(a)

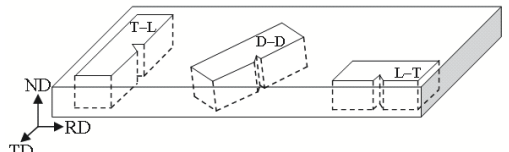

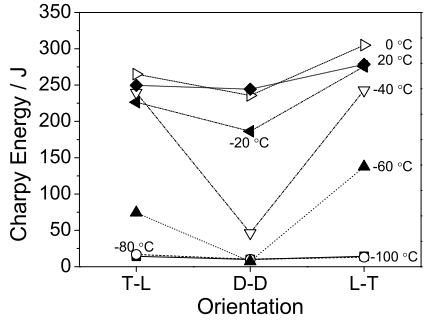

(b)

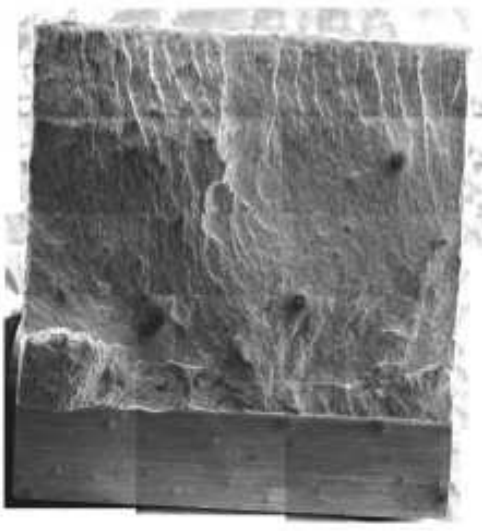

(d)

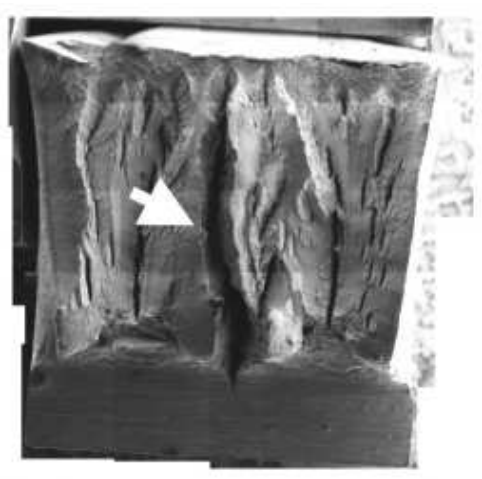

Figure 1: As-received X80 steel. (a) Orientations of Charpy test samples relative to steel plate, where 'RD', 'TD' and 'ND' stand for the rolling, transverse and normal directions. (b) Measured variation in Charpy toughness with notch orientation. (c) Lack of delamination in sample tested in the D-D orientation at $-60^{\circ} \mathrm{C}$. (d) Heavy delamination in sample tested in the $\mathrm{L}-\mathrm{T}$ orientation at $-60^{\circ} \mathrm{C}$. All the data illustrated here are from [27]. 
(a)

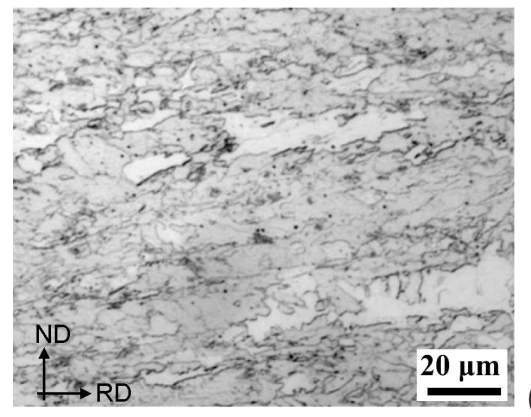

(c)

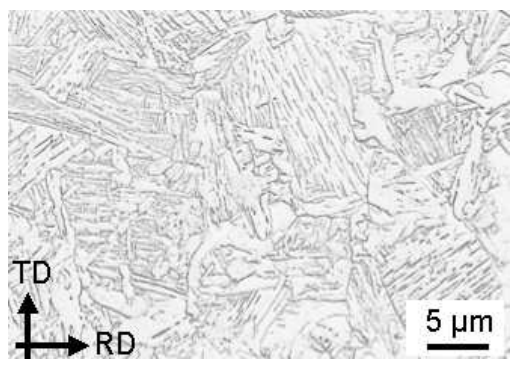

(b)

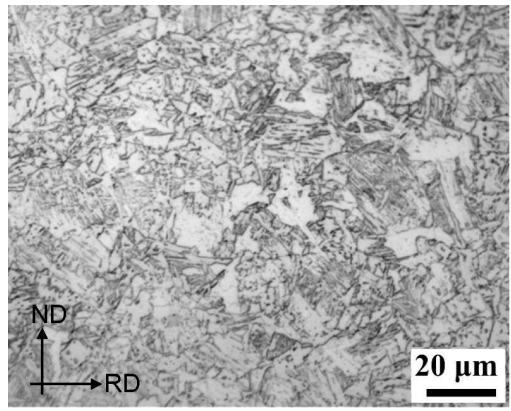

(d)

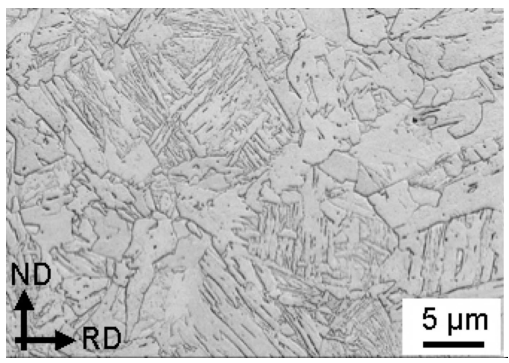

Figure 2: X80 steel. (a) In the as-received condition to illustrate the banding [27]. (b) The corresponding structure following heat treatment. (c,d) Higher magnification images of the heat-treated microstructure. 


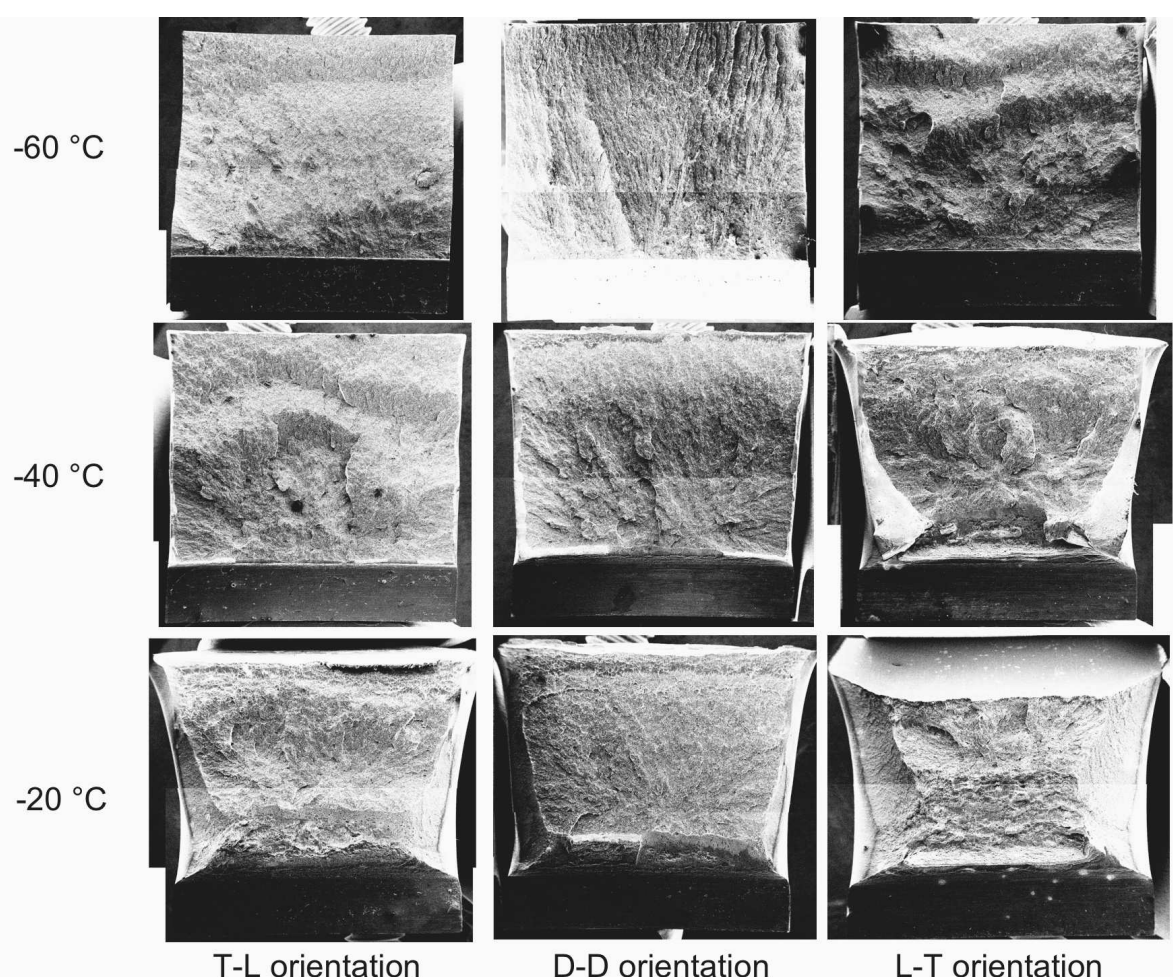

Figure 3: Fracture surfaces of Charpy specimens from heat-treated samples. 


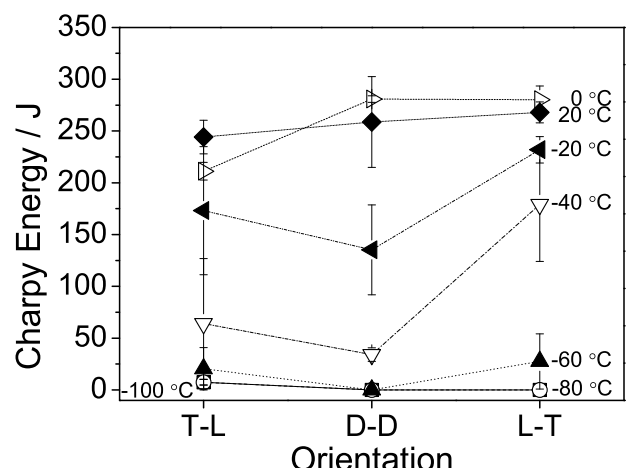

(a)

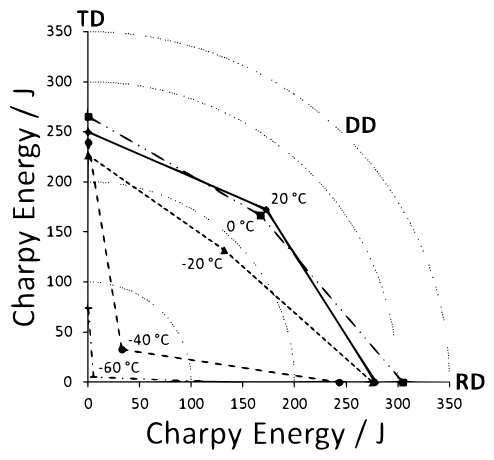

(b)

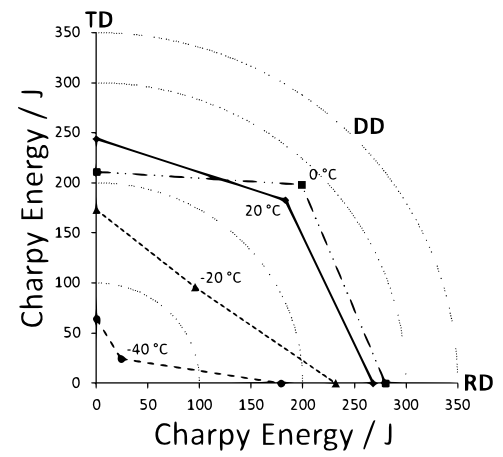

(c)

Figure 4: Charpy toughness data. (a) Raw data for heat-treated sample. (b) Anisotropy of as-received steel on a radial plot. (c) Anisotropy of heat-treated steel on a radial plot. 

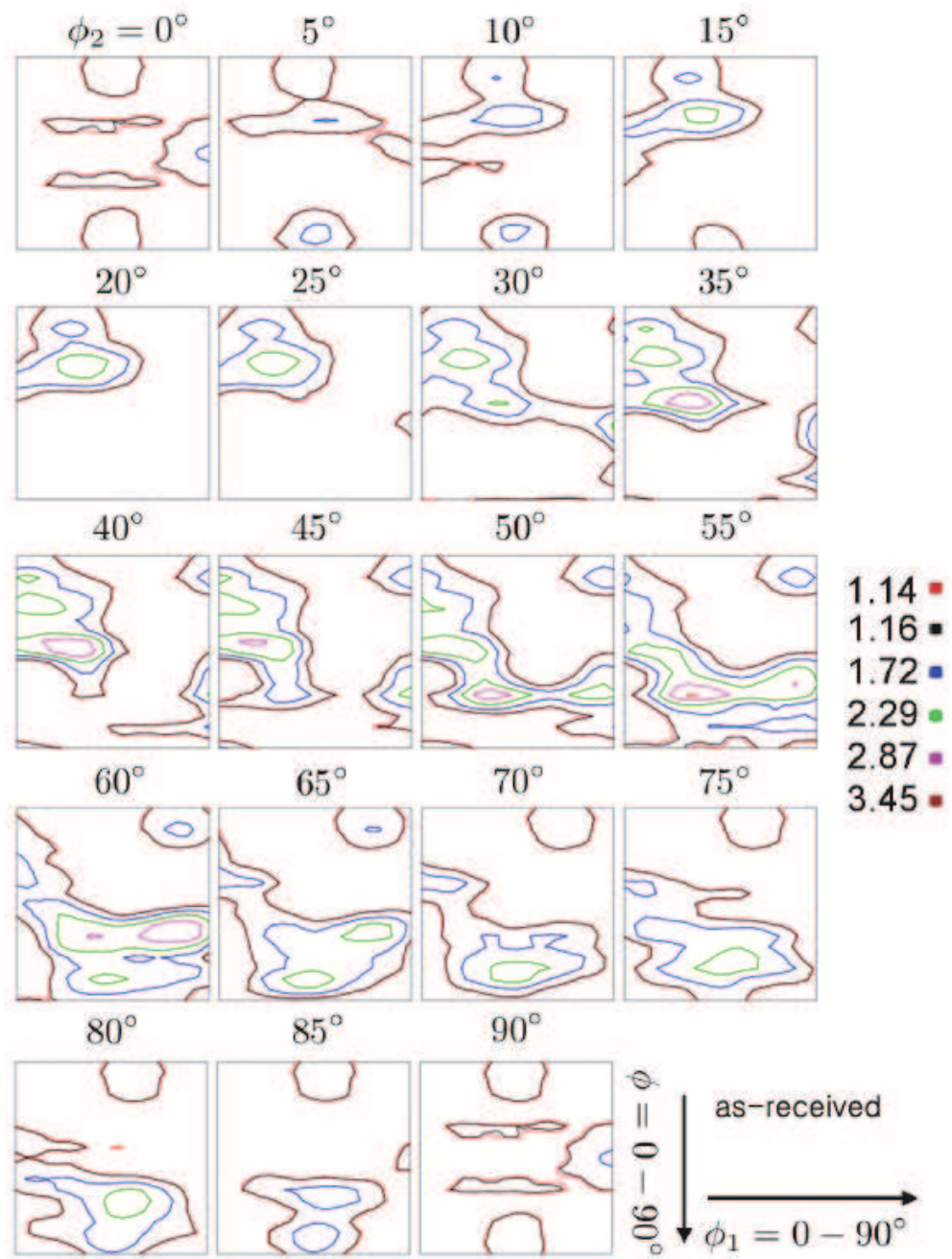

Figure 5: Orientation distribution for as-received steel. 


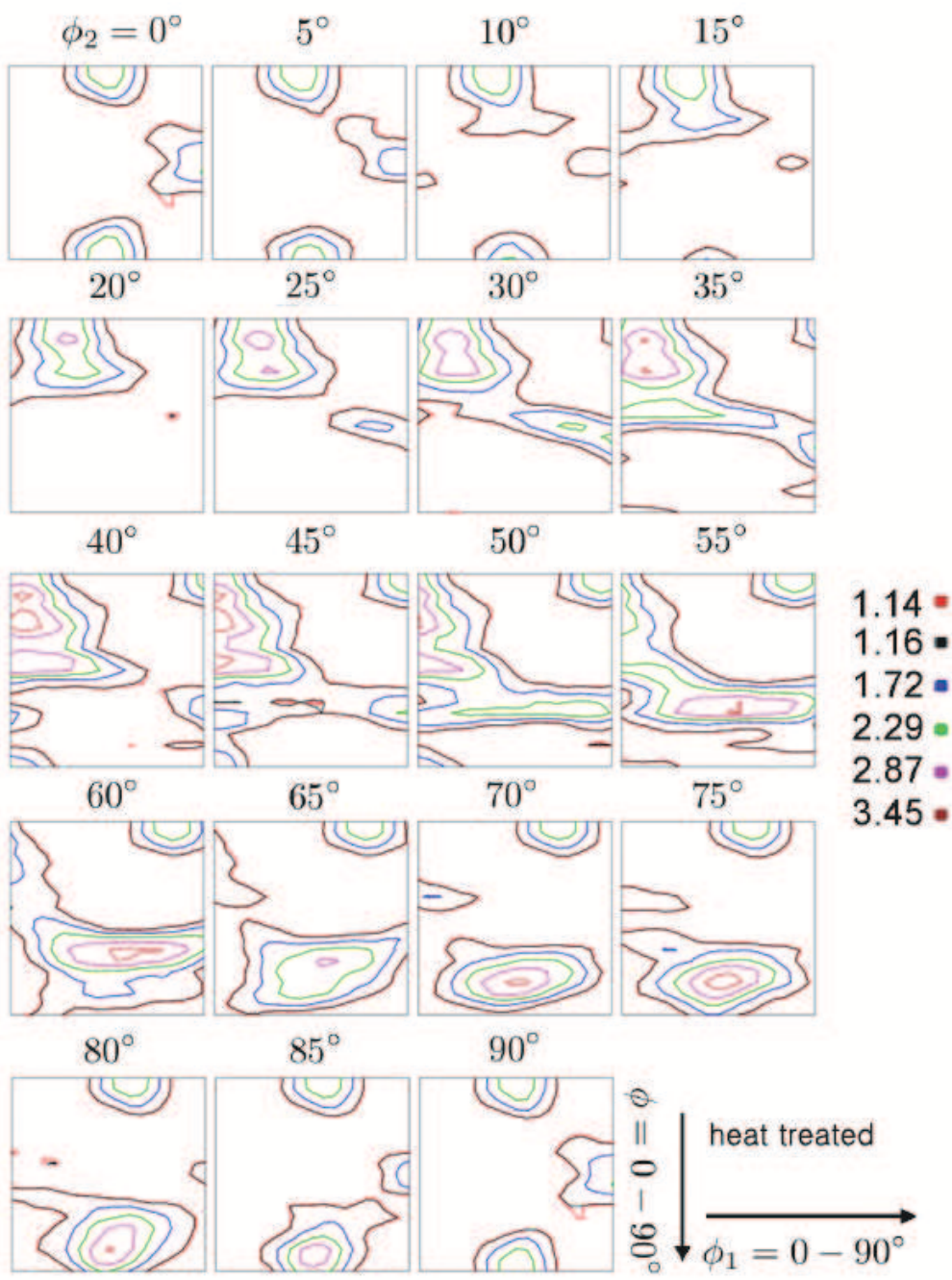

Figure 6: Orientation distribution for heat-treated steel. 

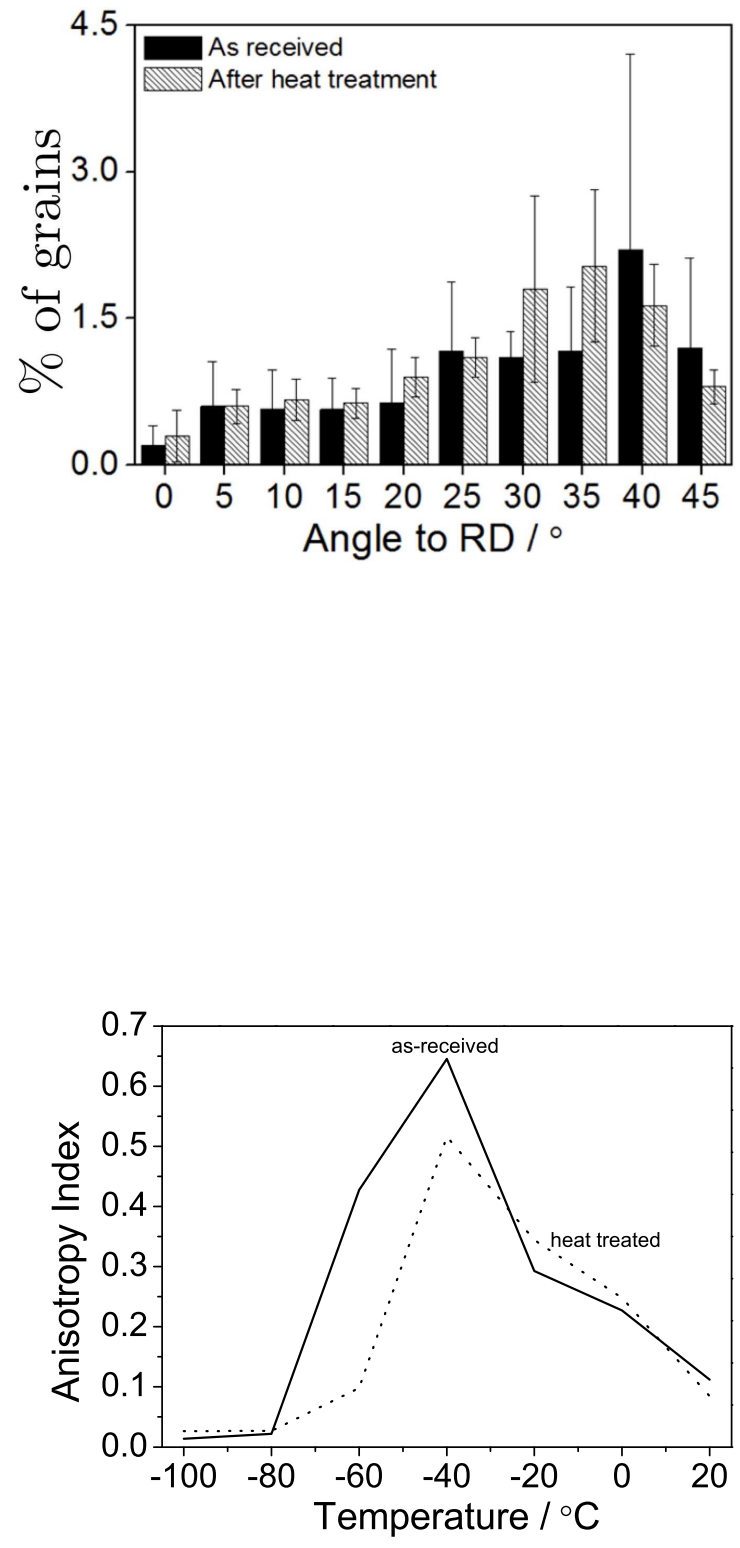

Figure 7: Percent of grains as a function of the angle between $\{100\}$ plane normals and the rolling direction, with a tolerance angle of $2.5^{\circ}$.
Figure 8: A comparison of the anisotropy indices for the as-received and heattreated samples. 
(a)
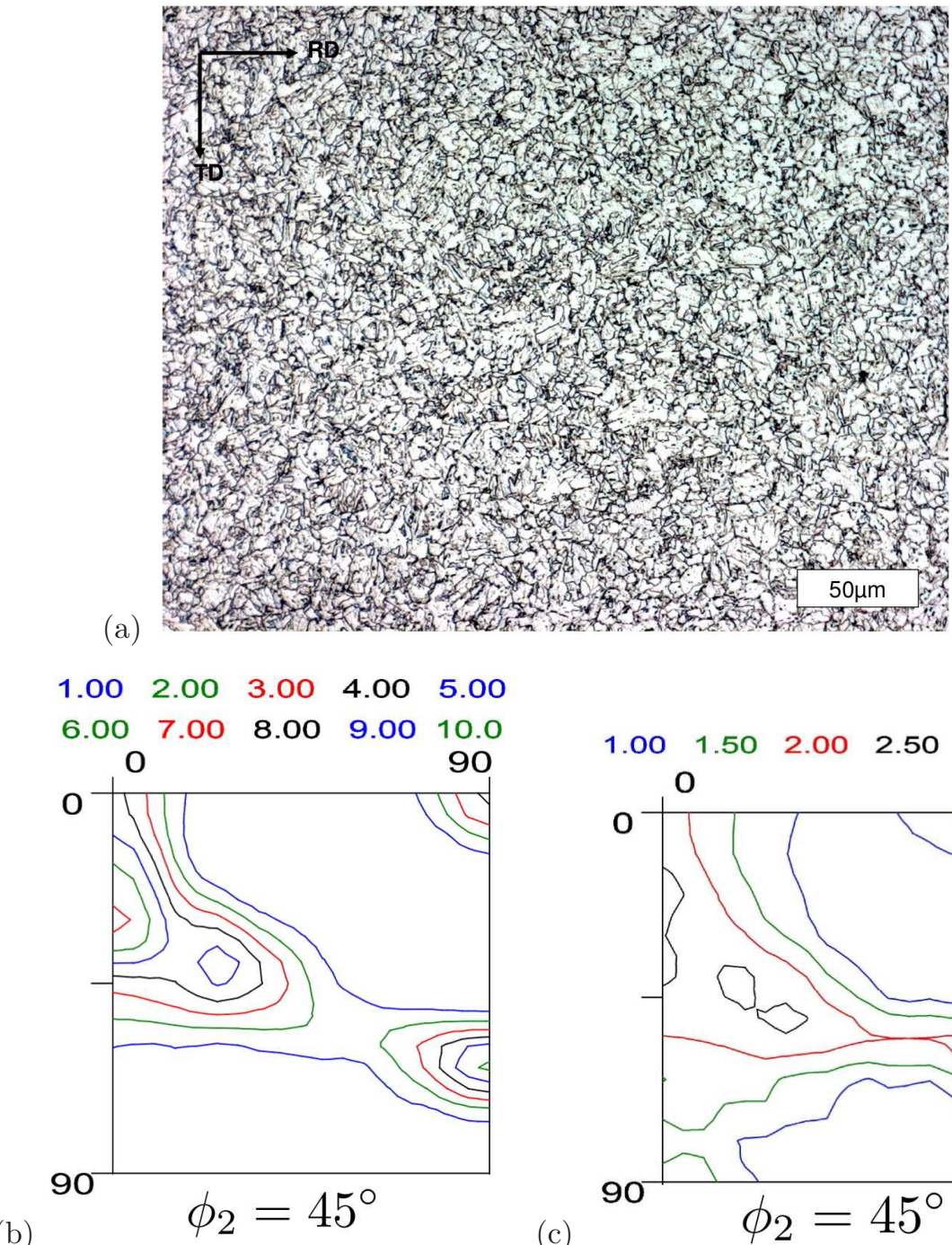

(c)

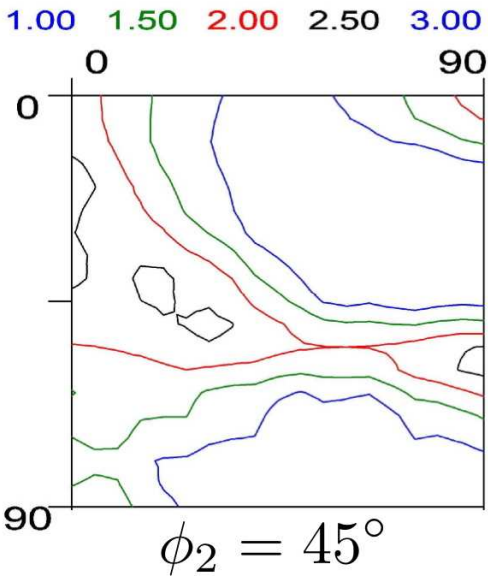

Figure 9: (a) Optical micrograph of sample heat-treated to produce bainite. (b) ODF $\left(\phi_{2}=\right.$ $45^{\circ}$ ) of the bulk texture of the as-received steel. (c) ODF $\left(\phi_{2}=45^{\circ}\right)$ of the bulk texture of the heat-treated sample. 


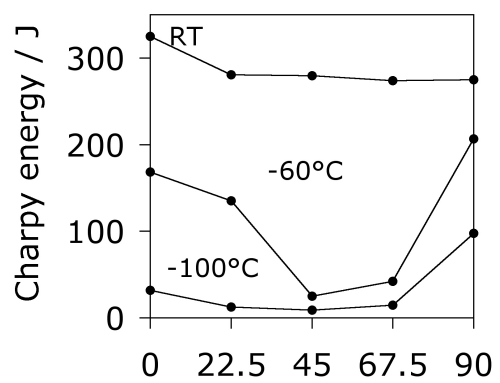

(a)

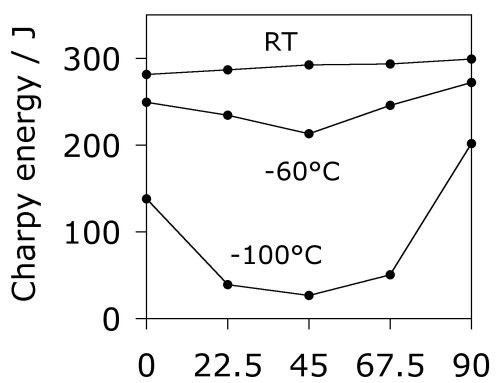

Angle to rolling direction

Figure 10: A comparison of the orientation dependence of the Charpy toughness for the as-received (X80-A3) and regenerated bainitic samples. 